\title{
Statistical Methods and Applications \\ Childcare and Participation at Work in North-East Italy. Why do Italian and Foreign Mothers Behave Differently? \\ --Manuscript Draft--
}

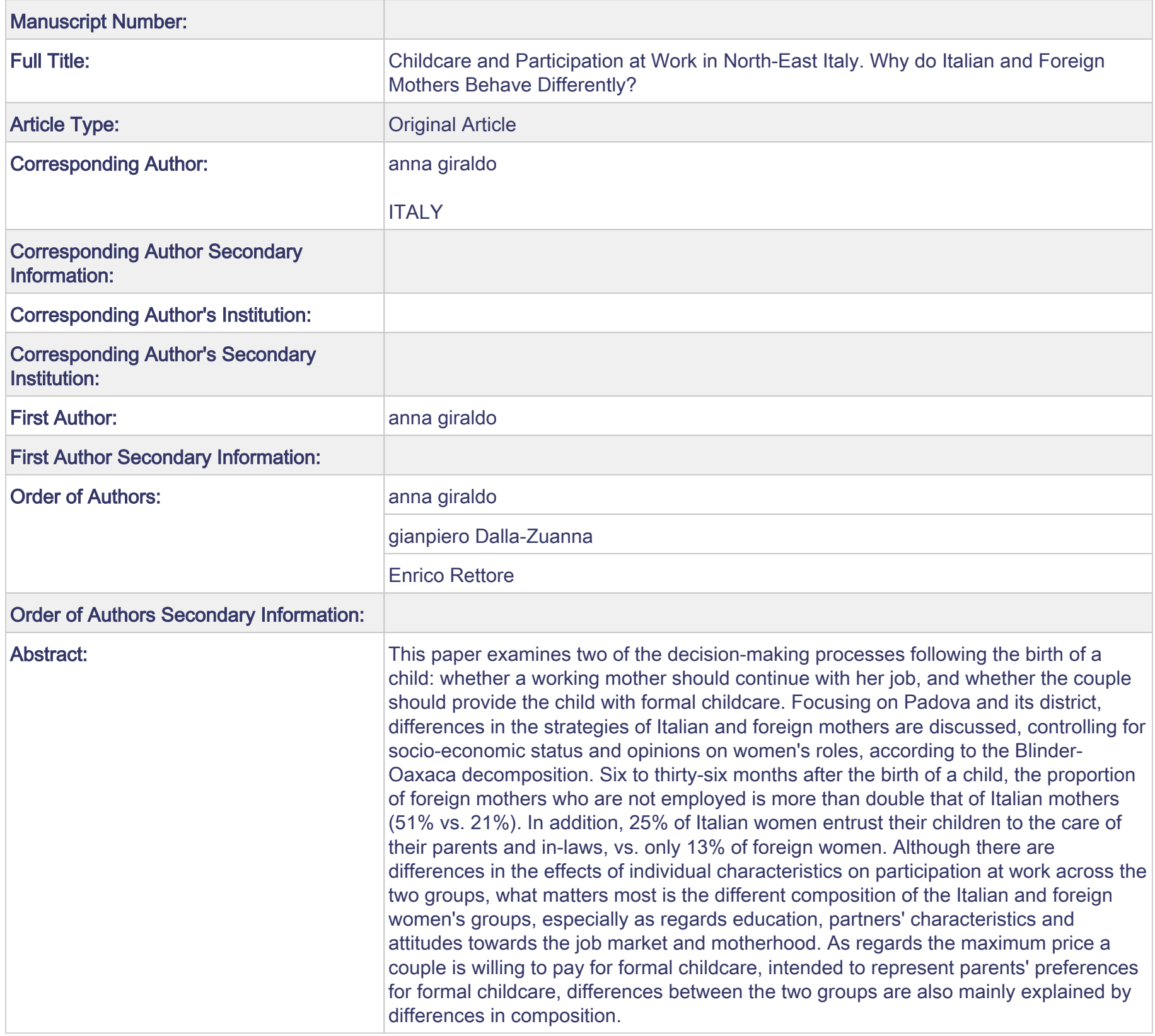



Why do Italian and Foreign Mothers Behave Differently?

\begin{abstract}
This paper examines two of the decision-making processes following the birth of a child: whether a working mother should continue with her job, and whether the couple should provide the child with formal childcare. Focusing on Padova and its district, differences in the strategies of Italian and foreign mothers are discussed, controlling for socio-economic status and opinions on women's roles, according to the Blinder-Oaxaca decomposition. Six to thirty-six months after the birth of a child, the proportion of foreign mothers who are not employed is more than double that of Italian mothers $(51 \%$ vs. $21 \%$ ). In addition, $25 \%$ of Italian women entrust their children to the care of their parents and inlaws, vs. only $13 \%$ of foreign women. Although there are differences in the effects of individual characteristics on participation at work across the two groups, what matters most is the different composition of the Italian and foreign women's groups, especially as regards education, partners' characteristics and attitudes towards the job market and motherhood. As regards the maximum price a couple is willing to pay for formal childcare, intended to represent parents' preferences for formal childcare, differences between the two groups are also mainly explained by differences in composition.
\end{abstract}

Keywords: Childcare, participation at work, foreign mothers, Blinder-Oaxaca decomposition

\title{
1. Introduction
}

The choice of working after the birth of a child and the type of childcare for the newborn baby if a woman works, depend on opportunity costs but also on women's preferences, which are partly influenced by cultural aspects ${ }^{1}$. In Italy, for example, the choice between formal childcare and childcare provided by grandparents is affected, among other things, by the family-oriented approach towards the care of children prevalent in the country (Jappens and Van Bavel, 2012).

Although several authors have studied the links between female labour force participation and childcare in Italy (see, e.g., Del Boca and Vuri 2007; Zollino 2008), fewer have examined the possible role of parents' nationality in these decisions.

The aim of this paper is to ascertain whether the different strategies to reconcile motherhood and labour force participation we found empirically between Italian and foreign mothers living in Italy are due to a compositional effect or whether there is something unmeasured that can be interpreted as a further "cultural" difference between them. Differences between the two groups were studied with respect to two decision-making

\footnotetext{
${ }^{1}$ We use here the ample definition of culture introduced by Guiso et al. (2006), page 23: "those customary beliefs and values that ethnic, religious, and social groups transmit fairly unchanged from generation to generation".
} 
processes: whether mothers should continue to work, and whether their children should be provided with formal childcare, measured by the maximum price a couple is prepared to pay for it; to this extent we control for socio-economic status, opinions regarding participation at work and motherhood and the availability of family networks, as a sort of measure of proximity to the family of origin.

As opposed to some reports in the literature (see mainly Del Boca et al., 2009, and Viitanen, 2005) jointly modelling participation at work and childcare choice, the approach followed in this work is mainly descriptive. In order to separate observable compositional differences from unobserved differences between Italian and foreign mothers, we chose here a method often used in applied economics to study wage differentials, the Blinder-Oaxaca decomposition. The differences in participation at work and childcare choices between Italian and foreign mothers turned out to be mainly due to compositional effects, and mothers, in spite of their culture, race and characteristics, react in the same way to the birth of a baby. Our results are in line with those of Andersson and Scott (2007), who found that the childbearing behaviour of foreign and native-born parents in Sweden were similar.

Our analysis refers to a specific urban area, the city of Padova and its suburbs (NorthEast Italy) and is based on data collected by an ad hoc survey carried out in April 2009 on the mothers of children aged 6-30 months. Despite the peculiarity and specificity of the data, which may affect the external validity of our study, we believe that the reasons our results are interesting go beyond the geographical area to which they refer. First, the socio-economic differential between Italian and immigrant women is particularly clear-cut in Padova. The local level of education is high for Italians (41\% of Italian mothers in our sample have university degrees, compared with an average of $19 \%$ for the whole country), presumably because of the presence of the large University of Padova, which offers a very wide spectrum of programmes. As a direct consequence of this high educational level, nearly $80 \%$ of Italian mothers in our sample work. Conversely, of the foreign mothers in Padova and its surroundings, only $18 \%$ have degrees and the proportion of women at work is just under $50 \%$. Second, both Italian and foreign women face the common problem of insufficient public childcare services. Summing up, the study of the choices of Italian and foreign women in Padova shed some light on how two populations very different in socio-economic status react to a common context, which provides a very limited supply of affordable, good-quality childcare.

The paper is organised as follows: section 2 summarises the theoretical background; section 3 describes Italy's (and Padova) characteristics as regards: childcare system, women 
participation to work and immigration. Section 4 introduces the survey on childcare

\section{Theoretical Background}

In modern societies, childcare choices are closely connected with the opportunity costs of children (Becker, 1981). A woman is prepared to stay at home, taking care of her children even after they are weaned and giving up her job, if the actualised flows of lost earnings are less than what she would have to pay for childcare. Accordingly, if childcare is hard to find and expensive, only women with high salaries will use them. Instead, if childcare is easily available and cheap (or free of charge, as in the case of grandparents), even women with low salaries will use it, in order to be able to go back to work soon after her child is weaned.

However, it is useful to integrate this perspective with the theory of preferences (Hakim 2000, 2003a). In developed societies, during childhood and adolescence, women develop specific preferences towards their careers and childcare. Hakim (2003b) does not question the usefulness of opportunity cost theory as a tool in understanding the choice between work and childcare, but she does claim that, given the size of the opportunity cost, women with different preferences make different economically rational choices. On one hand, a "family-oriented" woman will choose to work only if offered a high salary, since she only values the instrumental aspect of having a job. On the other, a "career-oriented" woman is ready to work even for a low salary because of her preference for work. Vitali et al. (2009) show that the distribution of women with respect to their attitude towards work vs. being housewives varies across countries. At the two poles are the Scandinavian countries, where career-oriented women prevail, and the Mediterranean countries, where family-oriented women prevail. A quite high proportion of Italian women may therefore be culturally oriented to stop work after a child is born, or may prefer to ask grandparents to look after the newborn baby. A family-oriented approach is also often transmitted from one generation to the next (see, e.g., Anderton et al. 1987; Booth and Kee 2009) and family-oriented parents may in turn be the children of parents more willing to make themselves available to look after their grandchildren.

In Europe, the strength of the "regulatory climate" (more or less family-oriented) acts on parents' decisions to entrust their children to grandparents (Jappens and Van Bavel, 2012). However, even after measuring the difference at individual and regional levels and controlling for many variables (including two measures of family-oriented regulatory climate and the 
availability of public childcare), there are still significant unexplained differences across European countries in the propensity to entrust children to grandparents, Italy, Spain and Greece having the highest proportions of this kind of childcare. This unexplained difference may be due to the absence, among the explanatory variables, of an indicator of the distance between the residences of parents and grandparents. Residential proximity between parents and adult children - which certainly fosters the idea of grandchildren being looked after by grandparents (Igel and Szydlik 2011) - is much higher in Italy, Spain and Greece than in the countries of Central and Northern Europe (Hank 2007).

To conclude, in the Italian context, the decision either to work or to take care of children is affected both by women's earning potential and by the availability of childcare services at affordable prices. However, the resulting equilibrium point is determined for every woman within a social context, such as the Italian one, imbued with strong family networks, resulting in a preference structure which is much more unbalanced (compared with the countries of Central and Northern Europe) towards the family than towards work. The "strong family ties" which characterise the European Mediterranean context (Reher 1998) may encourage mothers to stay in the job market, as the proximity between parents and grandparents may reduce the opportunity costs.

\subsection{Hypotheses on the Explanatory Variables}

Starting from the general theories of opportunity costs and preferences in the Italian context of strong family ties, some more clearly defined hypotheses can be formulated on the links between the two variables examined here - participation at work (WORK) and willingness to pay for childcare (PRICE) - and some characteristics of mothers and families. The discussion follows three general dimensions: socio-economic characteristics (which determine opportunity costs), family preferences, and the family network.

\subsubsection{Socio-economic Characteristics}

Number of children. As the number of young children living at home increases, it is harder for a woman to reconcile paid and unpaid work (Del Boca et al. 2009). In a context where parttime jobs are relatively scarce and most children leave their school buildings at 1 p.m., for many couples, the cost for caring for 2-3 young children may be higher than the woman's salary.

Education. For an educated woman, the opportunity cost of not having a job is higher, as 
returns to education are sizeable also in Italy $^{2}$. A woman's education, her partner's education and his work qualifications may be considered as good proxies not only for the opportunity cost but also for the overall family income. However, the hypothetical connections between partner's income and WORK and PRICE are ambiguous: on one hand, if the man is well-off, the woman may not be "forced" to work; on the other hand, as many wealthy men in NorthEast Italy are small-scale entrepreneurs, their female partners could collaborate with them in domestic enterprises.

Place of residence. In the Padova area, public and private childcare centres are not uniformly widespread: they are more common within city limits than in the suburbs and nearby municipalities. Consequently, for some low-paid women living outside the city, there is basically no choice between a job and housework, as cheap public childcare centres are nonexistent. Nor is it easy a priori to establish the sign of the effect of place of residence on PRICE. On one hand, the scarcity of services in rural areas should increase the price couples are prepared to pay for formal childcare. On the other, outside Padova the numbers of less wealthy working-class people are higher.

\subsubsection{Family Preferences}

As described above, both WORK and PRICE also depend on the culture of mothers. To some family-oriented mothers, having a paid job is mainly an instrumental device to raise the overall family income; to career-oriented mothers, it is (also) a matter of identity. In addition, some career-oriented women may be more influenced by the idea that early socialisation is highly positive for children, starting from the first year of life, whereas family-oriented women may think that, for very young children, nothing is better than being under the close protection of their parents, grandparents and relatives. According to our hypothesis, it should be easier for a family-oriented mother to give up working and less willing to pay high prices for formal childcare. Again, according to our hypothesis, the most career-oriented mothers should be the youngest, the most highly educated, and resident within the city. The propensity to take care of their children personally is also inversely related to children's age.

\subsubsection{Family Network}

The presence of healthy grandparents living near the couple should affect both WORK and PRICE. Close family networks help mothers to have jobs, not only when grandparents

\footnotetext{
${ }^{2} \mathrm{OECD}, 2004$, table A11.1a.
} 
provide full daily childcare, but also when they are available to help out in emergencies (a child's illness, a sudden change in the mother's time-schedule, etc). By the same token, the availability of free family childcare should lower the price a couple is prepared to pay for formal childcare.

\subsection{Some Characteristics of Foreign Mothers Living in Italy}

To our knowledge, there are no studies on how preferences interact with opportunity costs for women immigrating to Italy. Although they have the same problem of finding proper childcare as Italians, foreign women living in Italy may differ with respect to opportunity costs as well as preferences.

There could be several reasons why foreign mothers with young babies decide to defer work participation. First, immigrant women - particularly those from less developed countries in which women's participation in work is low - may be tied to a traditional view of women's role in society. Secondly, in Italy immigrant women with jobs typically receive low wages, so that their opportunity cost is also low. Thirdly, the particular Italian family context characterised, as already noted, by strong family networks and the lack of cheap childcare puts at a disadvantage foreign parents who would like to work after their child is weaned, partly because their family network is usually weak.

However, the decision to leave their native country to move to an economically more developed one may be selective towards women who wish to work, wanting to improve their social status. Also, in Italy - and especially in the North-East- a significant number of immigrant women come from Eastern Europe and the Balkans $53 \%$ in the Veneto, as of December 2009) where during the second half of the 20th century women's participation at work was particularly high and their fertility rate low or even very low. This situation is apparent from the results of a 2006 survey of the pre-adolescent children of immigrants (Gabrielli et al., 2013), in which foreign girls aged 10-14, especially those who had just arrived in Italy, were more career-oriented than their Italian peers: they wanted to have fewer children, were less attracted to domestic life, and more attracted by economic self-sufficiency associated with participation at work (Dalla-Zuanna et al., 2009, chapter 2). Clearly, these influences were absorbed by pre-adolescents from their family environment (Blau et al. 2013).

\section{Childcare, Women's Work and Migration in Contemporary Italy}

\subsection{The "Italian Approach" to Childcare}


In the late 20th century, private and public childcare services became widespread throughout 24 wealthiest countries, Italy came second lowest (UNICEF 2008). Some scholars argue that Italy, with other European countries such as Spain and Greece, may be grouped into the Southern or Mediterranean welfare model, characterised among other things by the minimal availability of childcare, partly compensated by a substantial family support system (Ferrera 1996; Del Boca et al. 2005; Del Boca and Vuri 2007; Zollino 2008; Saraceno and Keck 2011; Baizan 2009). Informal childcare (mainly provided by grandparents) offers some advantages, principally flexibility for particular family needs and the fact that it does not have to be paid for. However, this type of childcare also depends on several factors largely out of parents' control, especially the "availability" of healthy grandparents living at a reasonable distance, as well as their willingness to take care of their grandchildren (Keck and Saraceno 2008; Goodfellow and Laverty 2003). Although it is not universal, childcare by grandparents is usual for many Italian couples; and residential proximity between generations in Italy is in fact the highest in Europe (Hank 2007). Understandably, proximity between parents and grandparents is very often much lower among immigrant couples.

In 2002, according to data from the Italian Survey of Births, 50\% of Italian mothers with babies aged about 18 months took care of their own children; slightly more than $30 \%$ had grandparents or other relatives providing (informal) childcare, but only $20 \%$ used formal private or public care (Gabrielli and Dalla-Zuanna 2010). In 2005, the percentage of parental childcare fell to $46 \%$, while both formal and informal childcare increased (33\% and $21 \%$, respectively). In Italy, territorial differences in development, income and social organisation are considerable, and both public and private childcare services are mainly regulated locally. The Veneto region, the focus of our empirical analysis, lies in and around the national mean. The Veneto has also seen a rapid increase in formal childcare over the last 15 years, mainly due to the substantial involvement of catholic organisations in childcare services for children aged $0-3$, and partly financed by regional administration.

\subsection{The "Early Withdrawal" of Italian Mothers from the Labour Market}

The female employment rate in Italy is among the lowest in Europe. In 2009, only $46 \%$ of women aged 15-64 were employed, although this percentage varied significantly according to geographical area, women's age and their level of education. In the province of Padova, the employment rate of women aged 25-44 in 2009 was about 75\%, approximately three percentage points higher than the values for the whole Veneto region and fifteen percentage 
points higher than the rest of Italy.

Empirical literature suggests that one reason for the low level of female participation at work in Italy is how to reconcile work and childbearing. Although participation in the labour force for women aged 24-49 has increased over the years, there is still a substantial difference between the employment rates of women with children and those without (Righi 2003), which also tends to be greater for younger women. Casadio et al. (2008), using data from the Italian Survey of Births (2002), show that $20 \%$ of mothers stopped working for some length of time after their babies were born, and $14 \%$ decided to leave their jobs permanently. The variety of variables related to this early exit from the labour market include: age (younger mothers have a higher probability of leaving), education, availability of a family network (mainly grandparents), and degree of job protection. The positive influence of highly protected, stable jobs before pregnancy on the probability of being employed after childbearing was also found by Bratti et al. (2005). In general, problems for working mothers increase with the number of children born: the probability of leaving employment is higher for women with two or more children (Sabbadini, 2004). In 2009, mothers aged 16-64 who had always worked were asked if they had stopped work because of the birth of a child (Istat, 2011, page 154). On average, this proportion was not very high (15\%), but it doubled when all family reasons (marriage, birth of a child, need to assist an elderly person, etc.) were taken into consideration as a whole. These proportions were also higher among less educated women, mostly engaged in low-paid jobs.

\subsection{The "Explosion" of Migration in Italy}

The number of foreigners aged 0-17 in the Italian Population Registers has greatly increased in the last two decades, due to family migrations, family reunions, and births (Gabrielli et al., 2013). Data on this last aspect are the most reliable: births to at least one foreign parent increased from 5,000 in 1992 to about 100,000 in 2010. About 70\% of these newborns had both parents of foreign origin. This considerable increase is also demonstrated by stock data: foreigners aged 0-17 living in Italy numbered only 59,000 in the census of October 1991, compared with about 934,000 in the Population Register at the beginning of 2010, i.e., an increase from $0.6 \%$ to $9.1 \%$ of the population of the same age living in Italy. In the same period, children aged 0-17 made up $22 \%$ of the (legal) foreign population. Immigrants who live in Italy and who have children come from many countries, a characteristic which sets Italy apart from most other European countries and is due both to Italy's lack of a significant colonial history and to its geographical position 
As regards the city of Padova and its surroundings on January 1 2011, 92,000 foreigners (10\% of the total population) lived in the province of Padova, whereas foreign residents in the city numbered 31,000 (14\% of the total population). Also in this area of the country, the rate of growth has been impressive: only nine years before (January 1 2002), there had only been 22,000 foreigners in the province and 8,000 in the city. As regards births, during 2010, babies born to both foreign parents totalled $20 \%$ in the province and $29 \%$ in the city. In Padova in 2010, more than half the foreign residents came from Romania $(8,300)$ or Moldavia $(4,800)$, and the numbers of Nigerians, Moroccans, Albanians, Filipinos and Chinese all exceeded 1,000 individuals. These are the ethnicities most frequently represented in the province, but their concentration is lower than in the city ${ }^{3}$.

\section{A survey of childcare in Padova}

To examine couples' decisions about childcare, a sample survey, financed by the Veneto regional administration, was carried out in Padova and its surroundings in 2009. The reference population was composed of children aged 6-30 months, born in the area served by ULSS 16, the local agency for health services. In 2009, ULSS 16 covered 20 municipalities and 418,158 people (10\% foreigners). In order to obtain free healthcare, new parents are required to go to their local health office a few days after the birth of a child and choose a paediatrician who will take care of the child until its 14th birthday. The parents must also provide one or more telephone numbers, for rapid contacts with the health unit. The list of all newborns registered at ULSS 16 is a by-product of this administrative procedure. Full coverage of this list during 2006-08 was guaranteed, as the monthly number of births precisely matched those registered in the population registers of Padova's 20 municipalities.

Between July 12006 and June 30 2008, 7,454 newborns were registered by ULSS 16. Due to the birth of twins, triplets and (a very few) siblings born in the same period, the number of children corresponded to 7,278 mothers (our statistical population). Of these mothers, $16 \%$ were foreigners. A stratified sample was designed, with strata defined by municipality of residence (the city of Padova, the municipalities bordering it, and "rural" municipalities) and nationality. Italian and foreign mothers were considered in each geographical stratum. Foreign mothers were over-sampled to improve the precision of the estimates for this group.

In April 2009, 1,698 Italian and 411 foreign mothers were interviewed with a CATI

\footnotetext{
${ }^{3}$ See www.demo.istat.it.
} 
(Computer Assisted Telephone Interviewing) procedure, consisting of a questionnaire in Romanian or Albanian). Data were then post-weighted to obtain frequencies representative of the population as a whole. For detailed information on the survey (survey design, data collection, response rates and weighting procedure), see [names deleted to maintain the integrity of the review process] (2013).

\section{Descriptive statistics}

Our data provide an accurate picture of the population of mothers with children aged 6-36 months living in Padova and its surroundings. Tables 1-2 describe their characteristics with respect to the main variables of interest: nationality, childcare arrangements, and mothers' working status. Eighty four per cent of mothers were Italian; foreign mothers mainly came from Romania and Moldavia, but there were also quite a high percentage of African mothers.

Italian and foreign mothers care for their children in very different ways: $60 \%$ of foreign mothers take care of them alone, as opposed to only $30 \%$ of Italian mothers. Public childcare centres are more commonly used by foreigners, whereas the opposite is the case for private childcare (private childcare centres and baby-sitters). Lastly, perhaps as expected, only about one out of ten foreign babies is cared for by grandparents or other relatives, compared with $25 \%$ of Italian children. The percentage of Italian working mothers was about $79 \%{ }^{4}$ but only $49 \%$ for foreign mothers. The percentage of both Italian and foreign working mothers dropped after their children were born: before pregnancy, it was $87.8 \%$ for Italians and $60.5 \%$ for foreign mothers. Thus, the reduction was greater for foreign mothers $(-19 \%)$ than for Italian ones $(-10 \%)$.

** tables 1 and 2 around here **

In order to study the differences between Italian and foreign mothers with respect to work status and childcare, three groups of variables were identified: socio-economic characteristics, opinions, and availability of a family network. The socio-economic variables were: ages of mother/father and child, number of children living at home, education of mother/father, father's work qualification, and place of residence (Table 3). Although foreign mothers and fathers tended to be 4-5 years younger than Italian parents, they had more

\footnotetext{
${ }^{4}$ The percentage of working mothers also includes women on maternity leave.
} 
children than Italians. They also tended to have fewer years of schooling and - as expected the large majority were found at the bottom of the social ladder. Lastly, there were more foreign couples in the city.

** table 3 around here **

Principal component analysis (PCA) was used to summarise three questions concerning mothers' opinions (Table 4A). As PCA attributes 55\% of total variance to the first principal component, it was used to summarise items (see [names deleted to maintain the integrity of the review process], 2013 for details). The resulting variable (labelled joboriented) took on high values for mothers who considered that it was important for them to have a job (Table 4B). Generally speaking, Italian mothers were more job-oriented and foreign mothers more home-oriented, both when the questions were considered one by one and when they were collapsed into the synthetic index.

** table 4 around here **

Data on the distance between couples and their parents confirmed another major difference between Italians and foreigners. Results show that about $40 \%$ of Italian couples live $1 \mathrm{~km}$ or less away from at least one of their parents (13\% for foreign couples), whereas about $80 \%$ live no more than $10 \mathrm{~km}$ away from them (19\% for foreign couples). The large majority of the parents of Italian couples are pensioners and healthy, and are thus (theoretically) available to care for their grandchildren. Despite their younger age, the parents of foreign couples are more frequently in bad health or deceased, but the most important point is that, in $74 \%$ of cases, the nearest parent does not live in Italy (see for details [names deleted to maintain the integrity of the review process], 2013).

To summarise information on children's grandparents in a single variable describing the availability of a family network, a new variable was constructed, called family network, which took value 1 when there was at least one healthy grandmother ${ }^{5}$ living at a reasonable distance $\left(10 \mathrm{~km}\right.$ or less) ${ }^{6}$ (for details, see [names deleted to maintain the integrity of the

\footnotetext{
${ }^{5}$ Only grandmothers were considered, because in Italy, for a variety of reasons (division of roles in couples, even more pronounced in old couples, early retirement of women, etc.) only grandmothers are considered to be able to take care of small children.

${ }^{6}$ The lack of a family network has several causes: distance from grandparents' home, bad health or death of grandparents.
} 
review process], 2013). In our sample, the availability of a family network was quite high for

\section{Empirical strategy}

Descriptive statistics show that Italian and foreign mothers are quite different with respect to observable characteristics: compared with Italian women, foreign women are poorer, less educated, have weaker family networks, and are culturally more family-oriented. Our empirical strategy aimed at detecting whether the different behaviour towards participation at work and childcare arrangements could be entirely explained by these observable differences, or whether it was due to other non-observable factors.

The differences were examined with respect to two decisions: the working status of mothers with children under 3 years of age (WORK), and the maximum price a couple was willing to pay for formal childcare (PRICE). Although the first aspect is common to this type of study (see, e.g., Gabrielli and Dalla-Zuanna 2010), the second is less common (see, e.g., Bosi and Silvestri 2010) and is an alternative way of modelling the probability of enrolling a child in a daycare centre. The hypothesis was that the maximum price couples are prepared to pay for formal childcare is one way of characterising the value they attribute to the service, given their preferences and their income and has the advantage of being defined for all couples, whether they make use of formal childcare for their children or not.

To check whether these hypothetical links exist and how they differ between Italian and foreign mothers, Blinder-Oaxaca analysis was used, as applied to the regressions of WORK and PRICE on the set of explanatory variables described so far. The differences between the two groups were broken down into two components, differences due to the composition of the two groups, and to the effects the explanatory variables have on outcomes. In the following, the latter is interpreted as the component reflecting behavioural and cultural differences between Italian and foreign mothers not captured by the explanatory variables included in the model. 


\subsection{Work}

One traditional way of modelling the probability of participating at work for a mother with children aged 0-3 years is to use a non-linear model. The logical reason for using such a model (Probit, Logit, etc.) is that, if we wish to use the model to predict the expected value of the outcome for the units included in the sample, the linear probability model may produce predicted values outside the admissible range $(0,1)$ - a disappointing event which the nonlinear model, by definition, does not produce. But if we wish to use the model to identify the marginal effects of the explanatory variables - as in our case - there is no drawback to using the linear probability model. In fact, the marginal effects are much more easily derived and understood in a linear model (see discussion in Angrist and Pischke, 2009, section 3.4).

Let us consider a linear regression model $^{7}$, estimated separately for the two groups (Italian (I) and Foreign (F) mothers):

$$
W_{i g}=X_{i g} \beta_{g}+\varepsilon_{i g}, \quad g \in(I, F)
$$

where $W_{i g}$ represents the dummy variable working or not working, for mother $i$ in group $g$; $X_{i g}$ is a vector of observable characteristics; $\beta_{g}$ is a vector of parameters to be estimated, and $\varepsilon_{i g}$ is the error term capturing unobservable characteristics relevant for the outcome. Following Blinder (1973), Oaxaca (1973) and Oaxaca and Ransom (1994), the difference in mean outcome can be written as:

$$
\overline{W_{I}}-\overline{W_{F}}=\left(\bar{X}_{I}-\bar{X}_{F}\right) \hat{\beta}_{I}+\bar{X}_{F}\left(\hat{\beta}_{I}-\hat{\beta}_{F}\right)
$$

where $\overline{W_{g}}=N_{g}^{-1} \sum_{i=1}^{N_{g}} W_{i g}$. The first term on the right-hand side member is the difference between the two groups in participation at work, due to differences in observable characteristics; the second term is due to differences between the groups in the effect of each variable on the dependent variable. For linear models, the specific contribution of each explanatory variable can also be studied, at least as regards the explained part. For the unexplained part, caution must be taken in interpreting results, due to sensitivity to the scale

\footnotetext{
${ }^{7}$ In [names deleted to maintain the integrity of the review process] 2013 the results of the decomposition with the non-linear models are discussed.
} 
of the variables (see Jann, 2008)

\subsection{Willingness to pay for childcare services}

The variable willingness to pay for childcare services comes from two different questions. For mothers whose children were not in formal childcare, we observe the maximum price they were prepared to pay as the result of the sequence of questions designed to elicit the maximum price for childcare (see [names deleted to maintain the integrity of the review process], 2013 for details). In fact, for some of these mothers, we do not even observe the maximum price, since they are not willing to pay even the minimum price proposed in the sequence of questions (100 euro per month). In other words, all we know about them is that the maximum price they would pay is less than 100 euro/month.

Instead, for mothers whose children were already in formal childcare, rather than observing the maximum price they were willing to pay, we observe the price they actually pay which, by definition, is less than (or equal to) the maximum price they are willing to pay.

To exploit this mixed information - a point value for the maximum price for those not taking formal childcare and a lower limit on the maximum price for those not taking it - and to obtain a meaningful interpretation of the way in which the childcare choice is made, we model the dependence of maximum price for formal childcare which parents are willing to pay on a set of observable characteristics of the household. To estimate the parameters of this regression, we specify a tobit model to take into account the fact that the sample contains both right-censored observations - for those taking formal childcare we only know that their maximum price is higher than the price they actually pay, which is observable in our data and left-censored observations - for those unwilling to pay for formal childcare, even at the lowest price offered - we only know that their maximum price is lower than the lowest price they were offered.

In the end, the decision by the household to use formal childcare is made by comparing the price of the available service with the maximum price the household is prepared to pay for it: they take it if and only if the former does not exceed the latter. Apart from solving the specific problem here, modelling the continuous variable maximum price, instead of directly modelling the binary choice, provides an easily interpretable tool to answer such questions as: how many couples would change their childcare choice if the price of the service changed by a specified amount?

Formally, let $\mathrm{Y}^{*}$ be the maximum price the parents are prepared to pay for formal childcare, $\mathrm{Z}$ the binary variable for a child in formal childcare $(\mathrm{Z}=1), \mathrm{V}$ the binary variable for 
those not prepared to pay even the lowest price $(\mathrm{V}=1)$ and $Y$ the price observed in the data

in which :

$$
Y^{*}=\left\{\begin{array}{ccc}
Y & \text { if } & z_{i}=0 \cap v_{i}=0 \\
\geq Y & \text { if } & z_{i}=1 \\
\leq 100 & \text { if } & z_{i}=0 \cap v_{i}=1
\end{array}\right.
$$

The associated log-likelihood is:

$\log L(\beta \mid Y, X)=\sum_{i=1}^{n}\left[\left(1-z_{i}\right)\left(1-v_{i}\right) \ln \phi\left(y_{i} \mid X, \beta\right)+z_{i} \ln \left(1-\Phi\left(y_{i} \mid X, \beta\right)\right)+\left(1-z_{i}\right) v_{i} \ln \Phi(100 \mid X, \beta)\right]$

The contribution to the likelihood function provided by the units actually using the service is not the density function evaluated at the observed price, but the complement of the distribution function evaluated at the observed price, meaning that, for these units, the maximum price is higher than the observed price.

To obtain Blinder-Oaxaca decomposition, we evaluated the predicted value of the maximum price for each unit in the sample according to equation $3^{8}$. We then decomposed the difference between the average values of such predicted values in the same way as in equation 2.

\section{Results}

The sets of explanatory variables included in the two models are the same for both groups of mothers and refer to three broad dimensions: socio-economic characteristics, availability of a family network, and opinions.

\subsection{Work}

We found that mothers' socio-economic and demographic background influences their

\footnotetext{
${ }^{8}$ For Blinder-Blinder decomposition for the tobit model, see Bauer and Sinning (2010).
} 
working status to a very great extent (Table 6A). The higher the number of children, the larger higher - about twice as high - for the latter. The strength of other demographic variables is significant only for foreigners: work participation is lower among younger women, and among women with older partners. Education (as measured in years of schooling) has a positive effect on the probability of work for Italians but not for foreigners, but the opposite occurs for the husband's or partner's education: it is important for foreigners' work participation but not for that of Italians.

Major differences between Italians and foreigners also appear with respect to the role played by opinions: a home-oriented opinion significantly reduces the probability for Italian mothers but is not statistically significant for foreign women. Neither for Italian nor foreign women does the availability of a family network influence their choice to work, although the precision of the estimate for foreign mothers is very poor. This result points to the accessibility of formal childcare - if families can afford it - and suggests that Italian women can work even when they do not have the support of a family network.

Results from the Blinder-Oaxaca decomposition show that the great difference in participation at work between Italian and foreign mothers $-78.7 \%$ vs. $48.9 \%$ - is mainly due to observable differences in the characteristics of the two groups (the first term on the righthand side of equation 2). The percentage of difference explained by different composition is more that $90 \%$ (see Table 6B): in other words, if the two groups had the same composition with respect to the set of explanatory variables included in the regression, the difference between the two groups in work participation would drop dramatically (from .2973 to .0265).

The details of the decomposition clearly show that the gap in participation at work between the groups is mostly due to the level of qualification of husbands/partners, but the differences between foreign and Italian mothers are due to the number of children and to their mothers' level of education; opinions also have a quite important effect.

** table 6 around here $* *$

\subsection{Willingness to pay for formal childcare}

Regardless of their nationality, women with many children and/or very young babies are less willing to pay for childcare (see Table 7A). As in the case of WORK, results concerning education show that highly educated Italian mothers are willing to pay more, whereas for 
foreign couples it is the father's level of education which matters most. The returns to consequently, their level of education does not affect the maximum price they are willing to pay for formal childcare. Among foreign families, it is the father's level of education and his age which influence the willingness to pay and, consequently, women's labour contribution: if partners are younger and more educated, women report greater willingness to pay for formal childcare. Among Italian couples, the strength of opinions and family networks are highly significant. The most home-oriented Italian women and those with the strongest family networks are less willing to pay for formal childcare.

In conclusion, our expectations concerning the effect of covariates on the maximum price were met, but in different ways for Italian and foreign women: among the Italians, the opportunity cost of women's work and the family network play a clear-cut role. As in the previous analysis for WORK, among foreign couples the fathers' characteristics play a central role. For PRICE, opinions regarding family or jobs are central mainly for Italians, but also partly for foreign women.

$* *$ table 7 around here $* *$

The Blinder-Oaxaca decomposition for PRICE shows that the difference in the composition of the two groups explains most of the difference in their predicted values (69.2\%); the unexplained part accounts for the remaining 30.8\% (see Table 7B). In particular, the greatest differences between Italian and foreign mothers concern the number of children, their mothers' age, education, possibility of having a family network, and opinions regarding work.

Compared with WORK, where almost all differences are captured by differences in the composition of the two groups, in the case of PRICE, the differences partly lie in differences in the coefficients $(30 \%)$, i.e., variables act differently in the two groups. Although it is difficult to attribute this unexplained difference to specific variables (see section 6.1), exactly to which characteristics do Italian and foreign mothers react differently? Major differences in the coefficients are found for number of children, opinions and family network, all variables which also differentiate the groups as regards composition. That is, for Italian and foreign mothers, these variables differently affect the maximum price they are willing to pay for formal childcare. Why this happens (for example, why having more and younger children negatively influences PRICE more for foreign mothers than for Italian ones, when all other 
variables are controlled for) is not explained by the model. We can only suggest that it depends on cultural aspects and/or other unobservable characteristics of our sample.

\section{Discussion}

The starting point of our discussion is the great difference in the type of childcare arrangements and participation at work between Italian and foreign mothers. The numbers of foreign women staying at home with their children aged 0-3 were more than double those of Italian women (51\% vs. $21 \%$ ). The percentage of foreign women who leave their children with grandparents is half the corresponding percentage for Italian women (13\% vs. 25\%) and very few foreign households use private nurseries or have babysitters ( $8 \%$ vs. $30 \%$ for Italians). The only type of non-parental childcare with respect to which foreigners exceed Italians is the use of public childcare centres (17\% vs. $14 \%)$.

The Blinder-Oaxaca decomposition allows us to check whether these substantial differences are due to observable differences in the composition of the two groups or to the different statistical effect which the characteristics of the groups have on these outcome variables.

The determinants of the choices are not the same in the two groups: for Italian families, the characteristics of the woman (degree of education, job orientation, etc.) matter most, whereas for foreign families, the husband's characteristics (age and education) are of greater importance. However, these differences are minor when compared with the differences in group composition. In other words, if Italian and foreign mothers had the same composition with respect to the variables included in the regression (socio-economic variables, family network, family orientation), group differences would be $91 \%$ smaller for participation at work and $70 \%$ smaller for willingness to pay for childcare. With regard to the latter, although the unexplained part of the difference is less negligible, unfortunately it cannot be interpreted in the light of available information.

Thus, the mechanisms underlying the choices and constraints relating to work and childcare are basically homogeneous for Italian and foreign mothers. A similar result for Italian and foreign workers, although relating to unemployment, was recently obtained by Paggiaro (2013), who used different statistical techniques. The economic crisis of 2008 caused a rise in unemployment in Italy, which affected foreigners more than Italians. However, once a set of concomitant variables had been controlled for, the above author notes that there has been no discrimination against foreigners: the crisis affected them more seriously because they were practically all blue-collar workers, i.e., precisely those most 
affected by the fall in the number of available jobs.

The determinants which - from the theoretical point of view - may affect the employment status and childcare practices of couples are all present. Firstly, opportunity costs are closely associated in the expected direction with both WORK and PRICE, among Italians and foreigners: less wealthy and less educated couples and those with more than one child, especially if those children are very young, are less willing to pay for childcare. Secondly, preferences (oriented towards family vs. career) play a strong role, mostly among Italian mothers. Lastly, mainly among Italian mothers, the availability of family networks is crucial in influencing the price which couples are willing to pay for childcare.

According to our results, it will not be easy to increase the number of double-earner couples in the foreign group. Although the obstacles are mainly economic, they are also cultural: only the availability of very cheap childcare can drive them to look for work. But the cheapest childcare (their parents or parents-in-law) is rarely available to them, and the availability of cheap public kindergartens in Italy is unlikely to improve in the next few years, due to cuts in public spending. Hence, the only feasible solution is to turn to less expensive childcare options. In other countries - and to some extent also in Italy - alternative, cheaper solutions, partially financed by the state (such as Tagesmutter and/or self-organisation by mothers) have produced positive results, in terms of both quantity and quality.

Perhaps this is the pathway which should to be explored, to prevent the growing number of foreign children living in Italy from entering a state of double jeopardy: growing up in a poor family, because only the father holds an often low-paid job, and missing the opportunity of enjoying the stimulation of early socialisation through early contact with their peers outside the family environment.

\section{Acknowledgements}

$\operatorname{XXXX}$

\section{References}

[names deleted to maintain the integrity of the review process] (2013) XXXX, XXXX, Working paper Series, XXX, September 2013, XXX.

Andersson G. and Scott K. (2007) "Childbearing dynamics of couples in a universalistic welfare state: The role of labor market status, country of origin, and gender", Demographic Research, 17, 897938.

Anderton D.L., N. O. Tsuya, L. L. Bean and G. P. Mineau (1987) "Intergenerational transmission of relative fertility and life course patterns", Demography, 24, 4, 467-480.

Angrist J. and S. Pischke (2009), Mostly harmless econometrics, An empiricist's companion, 
Princeton University Press.

Baizan, P. (2009) "Regional child care availability and fertility decisions in Spain", Demographic Research, 21, 27, 303-842.

Bauer, T. and M. Sinning (2010) "Blinder-Oaxaca decomposition for Tobit models", Applied Economics, 42, 1569-1575.

Becker G. (1981) A treatise on the family, Harvard University Press, USA.

Blau, F.D., Kahn L.M., Liu A.Y-H., Papps, K.L. (2013) "The transmission of women's fertility, human capital, and work orientation across immigrant generations", Journal of Population Economics, 26, 405-435.

Blinder, A.S. (1973) "Wage Discrimination: Reduced Form and Structural Variables", Journal of Human Resources, 8, 436-455.

Booth A.L. and H. J. Kee (2009) "Intergenerational Transmission of Fertility Patterns", Oxford Bulletin of Economics and Statistics, 71, 2, 183-208.

Bosi, P. and P. Silvestri (2010) "Domanda di «child care» e modelli di welfare, in Le città incartate, M.Baldini, P.Bosi e P. Silvestri eds., Il Mulino, Bologna.

Bratti, M., E. Del Bono and D. Vuri (2005) "New mothers' labour force participation in Italy: the role of job characteristics", Labour, 19, 79-121.

Casadio, P., M. Lo Conte and A. Neri (2008) "Balancing work and family in Italy: New mothers' employment decisions after childbirth", Banca d'Italia, Temi di Discussione n.684, agosto 2008.

Dalla-Zuanna, G., P. Farina and S. Strozza (2009) Nuovi italiani. I giovani immigrati cambieranno il nostro paese?. Bologna: Il Mulino.

Del Boca, D. and D. Vuri (2007) "The Mismatch between Employment and Child Care in Italy: the Impact of Rationing". Journal of Population Economics, 20: 805-832.

Del Boca, D., M. Locatelli and D. Vuri (2005) "Child care Choices of Italian Households". Review of Economics of the Household, 3: 453-477.

Del Boca, D., S. Pasqua and C. Pronzato (2009) "Motherhood and market work decisions in institutional context: a European perspective", Oxford Economic Papers, 61, i147-1171.

Ferrera M. (1996) “The Southern Model in Social Europe". Journal of European Social Policy, 6(1): 17-37.

Gabrielli G. and G. Dalla-Zuanna (2010) "Formal and Informal Childcare in Italy and Its Regions", paper presented at the SIS Meeting of the Italian Statistical Society, Padova.

Gabrielli G., A. Paterno and G. Dalla-Zuanna (2013) "Just a matter of time? The ways in which the children of immigrants become similar (or not) to Italians", Journal of Ethnic and Migration Studies, DOI: 10.1080/1369183X.2013.815389.

Goodfellow, J. and J. Laverty (2003) "Grandparents supporting working families". Family Matters, 66: 14-19.

Guiso, L., P. Sapienza and L. Zingales (2006) "Does culture affect economic outcomes?" Journal of Economic Perspective, 20, 2, 23-48.

Hakim C. (2000) Work-lifestyle choices in the $21^{\text {st }}$ century: preferences theory, Oxford University Press, UK.

Hakim C. (2003a) "A new approach to explain fertility patterns: preference theory", Population and Development Review, 29, 3, 349-374.

Hakim C. (2003b) "Public morality versus personal choice: the failure of social attitude surveys" British Journal of Sociology, 54, 3, 339-345.

Hank K. (2007) "Proximity and contacts between older parents and their children: A European comparison", Journal of Marriage and the Family, 69, 157-173.

Igel C. and M. Szydlik (2011) Grandchild care and welfare state arrangements in Europe. Journal of European Social Policy 21(3): 210-224.

Istat (2011) "Rapporto Annuale. La situazione nel paese nel 2010", Roma.

Jann, B. (2008) "The Blinder-Oaxaca decomposition for linear regression models", Stata Journal, StataCorp LP, vol. 8(4), pages 453-479, December.

Jappens M. and J. Van Bavel (2012) "Regional family cultures and child care by grandparents in Europe", Demographic Research, 27, 4, 85-120.

Keck, W. and C. Saraceno (2008) "Grandchildhood in Germany and Italy: an exploration", in A. Leira e C. Saraceno (a cura), Childhood: Changing contexts, Comparative Social Research, vol. 25, 144- 
163, Emerald/Jai Press, Billingley (UK).

Oaxaca, R. (1973) "Male-Female Wage Differentials in Urban Labour Markets", International Economic Review, 14, 693-709.

Oaxaca, R. and M. Ransom (1994) "On Discrimination and the Decomposition of Wage Differentials", Journal of Econometrics, 61, 5-21.

OECD (2004) Education at a Glance. Paris.

Paggiaro A. (2013) "How do immigrants fare during the downturn? Evidence from matching comparable natives", Demographic Research, 28, 8, 229-258.

Reher, D.S. (1998) "Family Ties in Western Europe: Persistent Contrasts", Population and Development Review, 24(2): 203-234.

Righi, A. (2003) "Le tendenze di fecondità e di partecipazione femminile al mercato del lavoro", in Maternità e partecipazione delle donne al mercato del lavoro: tra vincoli e strategie di conciliazione, Cnel, Documenti $n^{\circ}$ 49, Roma 2 dicembre 2003.

Sabbadini, L.L. (2004) "Come cambia la vita delle donne", Ministero per le Pari Opportunità-ISTAT, Presidenza del Consiglio dei Ministri, ISTAT, Roma.

Saraceno, C. and W. Keck (2011)"Towards an integrated approach for the analysis of gender equity in policies supporting paid work and care responsibilities", Demographic Research, 25, 11, 371-406.

UNICEF (2008)The child care transition. Innocenti Report Card 8, UNICEF Innocenti Research Centre, Florence.

Viitanen, T. K. (2005) "Cost of childcare and female employment in the UK", Labour, 19, 149-170.

Vitali A., F.C. Billari, A. Prskawetz, M.R. Testa (2009) "Preference theory and low fertility: a comparative perspective", European Journal of Population, 25, 413-438.

Zollino, F. (2008) Il difficile accesso ai servizi di istruzione per la prima infanzia in Italia: i fattori di offerta e di domanda. Temi di Discussione, Bank of Italy, 30. 


\section{Tables}

Table 1: Mothers' nationality (column \%, weighted data)

\begin{tabular}{l|c}
\hline Italy & $\mathbf{8 4 . 2}$ \\
\hline Foreign country & $\mathbf{1 5 . 8}$ \\
\hline - Romania - Moldavia & 37.0 \\
- Ex-Yugoslavia & 12.3 \\
- Africa (Mediterranean region) & 12.8 \\
- Africa (other countries) & 16.6 \\
- Asia & 18.6 \\
- Other countries & 2.7 \\
\hline \multicolumn{2}{r}{} \\
\hline
\end{tabular}

Table 2: Childcare and mothers' working status by nationality (column \%, weighted data)

\begin{tabular}{|c|c|c|}
\hline Childcare & Italians & Foreigners \\
\hline Public childcare & 13.6 & 17.0 \\
\hline Private childcare & 23.3 & 4.6 \\
\hline Baby-sitters & 7.0 & 3.9 \\
\hline Grandparents or other relatives & 25.1 & 13.2 \\
\hline Parents & 31.0 & 61.3 \\
\hline Total & 100.0 & 100.0 \\
\hline Working Status & Italians & Foreigners \\
\hline Working & 72.4 & 42.3 \\
\hline On maternity leave & 6.3 & 6.6 \\
\hline Not working & 21.3 & 51.1 \\
\hline Total & 100.0 & 100.0 \\
\hline
\end{tabular}


Table 3: Socio-demographic characteristics by nationality (column \%, weighted data)

\begin{tabular}{|c|c|c|c|}
\hline Mean age (years) & Italians & Foreigners & Total \\
\hline Mothers & 36.1 & 31.1 & 35.3 \\
\hline Fathers & 39.1 & 35.3 & 38.5 \\
\hline Number of children & Italians & Foreigners & Total \\
\hline 1 & 51.1 & 43.9 & 50.0 \\
\hline 2 & 39.9 & 38.1 & 39.6 \\
\hline 3 & 7.4 & 13.6 & 8.4 \\
\hline 4 or more & 1.6 & 4.4 & 2.0 \\
\hline Total & 100.0 & 100.0 & 100.0 \\
\hline Mother's education & Italians & Foreigners & Total \\
\hline University & 40.7 & 18.4 & 37.2 \\
\hline High school & 45.9 & 49.8 & 46.5 \\
\hline Primary school & 13.4 & 31.8 & 16.3 \\
\hline Total & 100.0 & 100.0 & 100.0 \\
\hline Father's education & Italians & Foreigners & Total \\
\hline University & 33.1 & 15.8 & 30.4 \\
\hline High school & 47.7 & 46.2 & 47.5 \\
\hline Primary school & 19.1 & 38.0 & 22.1 \\
\hline Total & 100.0 & 100.0 & 100.0 \\
\hline Work qualification (father) & Italians & Foreigners & Total \\
\hline High & 34.2 & 1.9 & 29.8 \\
\hline Medium & 46.6 & 23.0 & 43.3 \\
\hline Low / unemployed & 19.2 & 75.1 & 26.9 \\
\hline Total & 100.0 & 100.0 & 100.0 \\
\hline Place of residence & Italians & Foreigners & Total \\
\hline City of Padova & 43.6 & 56.2 & 45.6 \\
\hline Suburbs & 28.6 & 23.3 & 27.8 \\
\hline Other municipalities & 27.8 & 20.5 & 26.7 \\
\hline Total & 100.0 & 100.0 & 100.0 \\
\hline
\end{tabular}


Table 4: Opinions on work and motherhood (column \%, weighted data) and "job-oriented" (descriptive statistics)

A. "In general, and not only taking into account your own situation, what is your opinion regarding these three statements?"

\begin{tabular}{|c|c|c|c|c|}
\hline & & Italians & Foreigners & Total \\
\hline \multicolumn{5}{|c|}{ A mother is only truly happy when she is at home with her child } \\
\hline I strongly agree & & 20.5 & 48.8 & 25.0 \\
\hline I agree & & 35.2 & 36.3 & 35.4 \\
\hline I disagree & & 35.3 & 13.6 & 31.9 \\
\hline \multirow{2}{*}{ I strongly disagree } & & 9.0 & 1.3 & 7.8 \\
\hline & Total & 100.0 & 100.0 & 100.0 \\
\hline \multicolumn{5}{|c|}{ It is right for a woman with children to continue working } \\
\hline I strongly agree & & 44.5 & 28.3 & 41.9 \\
\hline I agree & & 47.3 & 46.8 & 47.2 \\
\hline I disagree & & 6.4 & 20.1 & 8.6 \\
\hline \multirow[t]{2}{*}{ I strongly disagree } & & 1.8 & 4.8 & 2.3 \\
\hline & Total & 100.0 & 100.0 & 100.0 \\
\hline \multicolumn{5}{|c|}{ Small children may suffer if their mother works outside the home } \\
\hline I strongly agree & & 19.8 & 38.3 & 22.7 \\
\hline I agree & & 35.0 & 34.2 & 34.8 \\
\hline I strongly disagree & & 33.3 & 22.1 & 31.5 \\
\hline \multirow[t]{2}{*}{ I disagree } & & 11.9 & 5.4 & 10.9 \\
\hline & Total & 100.0 & 100.0 & 100.0 \\
\hline \multicolumn{5}{|l|}{ B. "Job-oriented" variable } \\
\hline Mean & & 1.87 & 1.04 & 1.74 \\
\hline Median & & 1.86 & 0.73 & 1.82 \\
\hline Range & & {$[-1.0 ; 4.2]$} & {$[-1.0 ; 4.2]$} & {$[-1.0 ; 4.2]$} \\
\hline
\end{tabular}

Table 5: Family network by nationality (column \%, weighted data)

\begin{tabular}{lccc}
\hline & Italians & Foreigners & Total \\
\hline No family network & 39.0 & 88.3 & 46.8 \\
Family network & 61.0 & 11.7 & 53.2 \\
\hline
\end{tabular}


Table 6: Results for WORK

\begin{tabular}{|c|c|c|c|}
\hline \multirow{2}{*}{ A. Linear probability model } & \multicolumn{2}{|c|}{ Regression model } & \multirow{2}{*}{$\begin{array}{c}\begin{array}{c}\text { Blinder-Oaxaca } \\
\text { decomposition }\end{array} \\
\text { Explained }\end{array}$} \\
\hline & Italians & Foreigners & \\
\hline Intercept & $0.5478 * *$ & 0.3645 & \\
\hline Number of children living at home & $-0.0350 * *$ & $-0.0623 *$ & $0.0066 * *$ \\
\hline Number of children aged 6-36 months & $-0.1049 * *$ & -0.1081 & $0.0049 *$ \\
\hline \multicolumn{4}{|l|}{ Place of residence (city of Padova) } \\
\hline Suburbs & -0.0218 & -0.0651 & -0.0011 \\
\hline Other municipalities & 0.0057 & 0.0284 & 0.0004 \\
\hline Age of mother (years) & -0.0002 & $0.0204 * *$ & -0.0012 \\
\hline Age of father (years) & -0.0004 & $-0.0173 * *$ & -0.0015 \\
\hline Child's age (months) & -0.0014 & 0.0032 & 0.0004 \\
\hline Mother's education (years) & $0.0099 * *$ & -0.0077 & $0.0177 * *$ \\
\hline Father's education (years) & -0.0016 & $0.0289 * *$ & -0.0027 \\
\hline \multicolumn{4}{|l|}{ Father's work qualification (low / unemployed) } \\
\hline Middle/High qualification & $0.3183 * *$ & $0.1534 *$ & $0.1912 * *$ \\
\hline Family network ( 1 if available) & 0.0141 & 0.1186 & 0.0070 \\
\hline Opinions (- Home-oriented vs. Job-oriented +) & $0.0599 * *$ & -0.0012 & $0.0491 * *$ \\
\hline Number of observations & 1,692 & 402 & \\
\hline \multicolumn{4}{|c|}{ B. Oxaca decomposition for linear probability model } \\
\hline Prediction for Italian mothers & 0.7867 & & \\
\hline Prediction for foreign mothers & 0.4894 & & \\
\hline Differences & 0.2973 & & \\
\hline Explained & 0.2708 & $(91.1 \%)$ & \\
\hline Unexplained & 0.0265 & $(8.9 \%)$ & \\
\hline
\end{tabular}

$* * \mathrm{p}<0.05, * 0.05<\mathrm{p}<0.10$. 
Table 7: Results for PRICE

\begin{tabular}{|c|c|c|c|}
\hline \multirow{2}{*}{ A. Tobit model (in EUR) } & \multicolumn{2}{|c|}{ Regression model } & \multirow{2}{*}{$\begin{array}{c}\begin{array}{c}\text { Blinder-Oaxaca } \\
\text { decomposition }\end{array} \\
\text { Explained } \\
\end{array}$} \\
\hline & Italians & Foreigners & \\
\hline Intercept & -169.4850 & 120.2752 & \\
\hline Number of children living at home & $-36.3063 * *$ & $-18.1358 * *$ & $4.3213 * *$ \\
\hline Number of children aged 6-36 months & 3.9268 & $-61.7425 * *$ & -0.1150 \\
\hline $\begin{array}{l}\text { Place of residence (city of Padova) } \\
\text { Suburbs } \\
\text { Other municipalities }\end{array}$ & $\begin{array}{l}-6.9960 \\
-31.6005^{*}\end{array}$ & $\begin{array}{r}28.1720 \\
7.1174\end{array}$ & $\begin{array}{l}-0.3627 \\
-2.7125^{*}\end{array}$ \\
\hline Age of mother (years) & $3.6920 * *$ & 2.2222 & $19.3545 * *$ \\
\hline Age of father (years) & 0.0348 & $-2.4371 *$ & 0.1366 \\
\hline Child's age (months) & $3.0125 * *$ & $1.9476^{*}$ & $-0.7814 * *$ \\
\hline Mother's education (years) & $13.9777 * *$ & 2.8284 & $22.8563 * *$ \\
\hline Father's education (years) & 1.9112 & $4.6907 *$ & 2.7233 \\
\hline $\begin{array}{l}\text { Father's work qualification (low / unemployed) } \\
\text { Middle/High qualification }\end{array}$ & 20.7727 & 10.8817 & 11.9484 \\
\hline Family network (1 if available) & $-58.6916 * *$ & 43.0615 & $-29.4778 * *$ \\
\hline Opinions (- Home-oriented vs. Job-oriented +) & $62.1188 * *$ & $14.6575 * *$ & $50.5390 * *$ \\
\hline $\begin{array}{l}\text { Number of observations (Total) } \\
\text { Left-censored } \\
\text { Uncensored } \\
\text { Right-censored }\end{array}$ & $\begin{array}{l}1,686 \\
377 \\
692 \\
617\end{array}$ & $\begin{array}{c}401 \\
73 \\
238 \\
90\end{array}$ & \\
\hline \multicolumn{4}{|l|}{ B. Oxaca decomposition for tobit model } \\
\hline $\begin{array}{l}\text { Prediction for Italian mothers } \\
\text { Prediction for Foreigner mothers } \\
\text { Differences } \\
\text { Explained } \\
\text { Unexplained }\end{array}$ & $\begin{array}{c}280.624 \\
167.296 \\
113.328 \\
78.430 \\
34.898\end{array}$ & $\begin{array}{l}(69.2 \%) \\
(30.8 \%)\end{array}$ & \\
\hline
\end{tabular}

$* * p<0.05, * 0.05<p<0.10$ 


\title{
Childcare and Participation at Work in North-East Italy.
} Why do Italian and Foreign Mothers Behave Differently?

\author{
Anna Giraldo $^{\S}$, Gianpiero Dalla-Zuanna ${ }^{\S}$, Enrico Rettore ${ }^{\#}$ \\ ${ }^{\S}$ Department of Statistical Sciences, University of Padova, Italy \\ ${ }^{\#}$ Department of Economics and Management, University of Padova, Italy
}

Corresponding author:

Anna Giraldo

Department of Statistical Science

University of Padova

via Cesare Battisti 241

35121 Padova

Italy

Phone: +390498274185

Fax: +390408274170

Email: anna.giraldo@unipd.it 